\title{
Correction to: Sleeve Gastrectomy and Anterior Fundoplication (D-SLEEVE) Prevents Gastroesophageal Reflux in Symptomatic GERD
}

\author{
Gianmattia del Genio $^{1} \cdot$ Salvatore Tolone ${ }^{1}$. Claudio Gambardella ${ }^{1}$ • Luigi Brusciano ${ }^{1}$ • Mariachiara Lanza Volpe ${ }^{1}$. \\ Giorgia Gualtieri ${ }^{1} \cdot$ Federica del Genio ${ }^{1}$. Ludovico Docimo ${ }^{1}$
}

Received: 20 January 2021 / Revised: 20 January 2021 / Accepted: 20 January 2021 / Published online: 4 February 2021

(C) Springer Science+Business Media, LLC, part of Springer Nature 2021

Correction to: Obesity Surgery (2020) 30:1642-1652

https://doi.org/10.1007/s11695-020-04427-1

In the original article metadata the name of author Mariachiara Lanza Volpe was presented incorrectly. The author given name should be Mariachiara and the author family name should be Lanza Volpe.

Publisher's note Springer Nature remains neutral with regard to jurisdictional claims in published maps and institutional affiliations.

The online version of the original article can be found at https://doi.org/ 10.1007/s11695-020-04427-1

Gianmattia del Genio

gdg@doctor.com

1 Center of Esophago-gastric and Obesity Surgery (E.G.O.), XI

Division and Bariatric Surgery, University Vanvitelli, Naples, Italy 